\begin{tabular}{c} 
JOURNAL OF APPLIED SMART ELECTRICAL \\
Vol. 2 No. 2(2021) $64-70 \quad$ ISSN Media Elektronik: 2723-5467 \\
\hline
\end{tabular}

\title{
Desain Robot Pengintai Segala Medan Dengan Kendali Wireless PS 2
}

\author{
Mayastri Devana ${ }^{1}$, Tresna Dewi ${ }^{2}$, Nyayu Latifah Husni ${ }^{3}$, Pola Risma ${ }^{4}$, Yurni Oktarina ${ }^{5}$ \\ 1,2Jurusan Teknik Elektro, Politeknik Negeri Sriwijaya \\ ${ }^{1}$ mayastridevana02052@gmail.com, ${ }^{2}$ tresna_dewi@polsri.ac.id, ${ }^{3}$ nyayu_latifah@polsri.ac.id, ${ }^{4}$ polarisma@polsri.ac.id, \\ ${ }^{5}$ yurni_oktarina@polsri.ac.id
}

\begin{abstract}
A mobile robots is one of the solution to overcome the deficiency of security surveillance camera systems that are static in nature, which are vulnerable to blind spots on the results of their observations. In this research, the surveillance robot is made to resemble the shape of a mars rover robot that is applied to be able to move more freely to stalk areas and be able to navigate on uneven surfaces. The movement of the surveillance robot wheel uses a wireless PS 2 remote control and is driven by a DC motor rotation as its main drive. The connection between the PS2 Remote Control and the surveillance robot is by using the Arduino Uno. In addition, this robot will be equipped with a camera that will send visual surveillance results from the robot to the smartphone.
\end{abstract}

Keywords: Mobile Robot, Mars Rover Robot, Wireless PS 2 Remote Control, Camera.

\begin{abstract}
Abstrak
Mobile robot merupakan solusi untuk mengatasi kekurangan sistem kamera pengintai keamanan yang bersifat statis, yaitu rentan terdapat area titik buta pada hasil pengamatannya. Pada penelitian ini robot pengintai dibuat menyerupai bentuk mars rover robot yang diterapkan untuk dapat lebih leluasa bergerak mengintai area-area dan mampu bernavigasi pada permukaan yang tidak rata. Pergerakan roda robot pengintai ini menggunakan wireless PS 2 remote control dan digerakkan dengan putaran motor DC sebagai penggerak utamanya. Koneksi antara PS2 Remote Control dengan robot pengintai adalah dengan menggunakan arduino uno. Selain itu robot ini akan dilengkapi dengan kamera yang akan mengirimkan hasil visual pengintaian dari robot ke smartphone.
\end{abstract}

Kata kunci: Robot Mobil, Mars Rover Robot, Wireless PS 2 Remote Control, Kamera.

Diterima Redaksi : 21-07-2021 | Selesai Revisi : 15-12-2021 | Diterbitkan Online : 31-12-2021

\section{Pendahuluan}

Saat ini teknologi elektronika semakin berkembang pesat, khususnya teknologi yang berhubungan dengan pengontrol otomatis, sehingga manusia selalu mencari proses otomatisasi yang pengoprasiannya dapat digunakan dengan mudah. Salah satu teknologi elektronika otomatis yang berkembang saat ini adalah bidang robotika. Saat ini robot banyak digunakan dalam berbagai bidang kehidupan [1]-[8]. Salah satu jenis robot yang paling banyak digunakan karena kemampuan pergerakannya adalah mobile robot [8]-[14]. Dalam bidang militer, robot dapat digunakan sebagai alat pengintai atau pengawas [10]. Dalam hal ini robot pengintai dapat diterapkan untuk mengintai areaarea tertentu dan yang medannya tidak dapat dilewati oleh manusia, karena ukurannya kecil maka robot dapat lebih leluasa bergerak di area-area sempit yang umumnya tidak mampu dilewati oleh manusia.

Pergerakan robot pengintai dapat dikendalikan secara otomatis dengan menggunakan input pengolahan citra [14][15] dan gerakan atau isyarat tangan, maupun secara manual dengan menggunakan remote control [16][17]. Penggunaan remote control atau pengendali jarak jauh adalah cara mudah untuk mengendalikan gerak robot tanpa harus berkutat dengan programing yang rumit maupun menggunakan berbagai jenis kecerdasan buatan [18]-[30].

Salah satu jenis robot yang bisa dijadikan robot pengintai adalah robot yang mirip dengan mars rover. Robot seperti ini diharapkan mampu bergerak 
di semua bidang dan melewati rintangan dengan mudah.

Paper ini membahas desain robot pengintai dengan mengambil bentuk seperti mars rover robot. Navigasi robot dilakukan melalui remote control Joystick Wireless Berbasis Arduino. Robot pengintai yang didesain pada penelitian ini menggunakan sensor jarak jenis ultrasonik untuk mampu menghindari rintangan yang ditemui secara otomatis. Pengendalian jarak jauh robot dilakukan melalui kamera PI sehingga operator mampu melihat lingkungan disekitar robot dan memutuskan gerak dan navigasi robot. Paper ini juga dilengkapi dengan simulasi untuk menunjukkan desain gerakan robot.

\section{Metode Penelitian}

Pada Gambar 1 menunjukkan diagram kerja robot pengintai. Input gerak atau data protocol stik PS2 berfungsi untuk mengatur komunikasi dengan kontroler agar dapat menggerakkan robot pengintai sesuai perintah yang di berikan. Sensor HC-SR04 mendeteksi jarak halangan dengan menggunakan data output sensor agar tidak terjadi tabrakan.

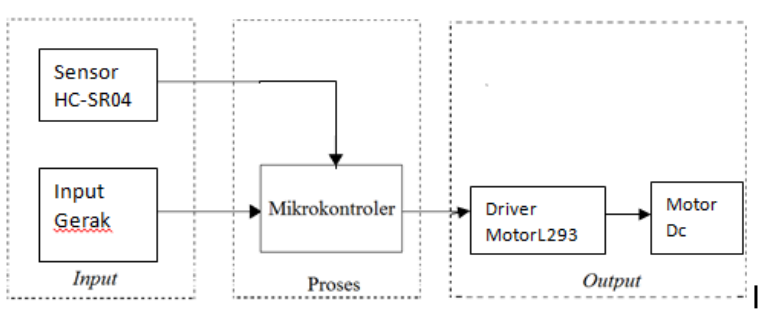

Gambar 1 Diagram Skematik Cara Kerja Alat Penelitian

Penjelasan proses metode penelitian pada (Gambar 1), yaitu:

a. Input Gerak : Input gerak atau data protocol stik PS2 berfungsi untuk mengatur komunikasi dengan kontroler agar dapat menggerakkan robot pengintai sesuai perintah yang di berikan.

b. Sensor HC-SR04 : Sensor jarak pada rangkaian ini berfungsi untuk mendeteksi adanya obstacle (halangan) yang menghalangi jalannya robot.

c. Mikrokontroller : Mikrokontroller digunakan untuk mengolah data yang dikirim dari wireless receiver stick $P S 2$. Kemudian mikrokontroller akan memerintahkan sebuah perintah ke driver motor.

d. Driver Motor : Driver motor digunakan untuk menerima perintah dari arduino, setelah itu driver motor akan memerintahkan motor DC sebagai roda kanan dan roda kiri.

e. Motor DC yang digunakan adalah enam buah, sebagai roda kanan dan kiri di posisi depan, tengah, dan belakang.

\subsection{Design Mekanik}

Pada Gambar 2,3, dan 4 menunjukkan rancangan dari mobile robot pengintai yang didesain pada penelitian ini. Mobile robot ini memiliki detail ukuran sebagai berikut, panjang robot $40 \mathrm{~cm}$, tinggi robot $26 \mathrm{~cm}$, lebar robot $30 \mathrm{~cm}$, dan berat robot $1,5 \mathrm{~kg}$ . Pada bagian base (tingkat utama) mobile robot ini telah di rancang dan diatur sebagai tempat komponen-komponen utama mobile robot ini, seperti

Receiver stik PS2, ip kamera, mikrokontroler 328, driver motor L298N, dan motor DC. Pada bagian depan base mobile robot ini memilik 1 sensor ultrasonic. pada posisi kanan dan kiri robot ini memiliki masing-masing 1 sensor ultrasonik. Pada bagian belakang mobile robot ini dipasangkan baterai sebagai power utama penggerak mobile robot dengan tegangan sebesar $2200 \mathrm{mAh}$.

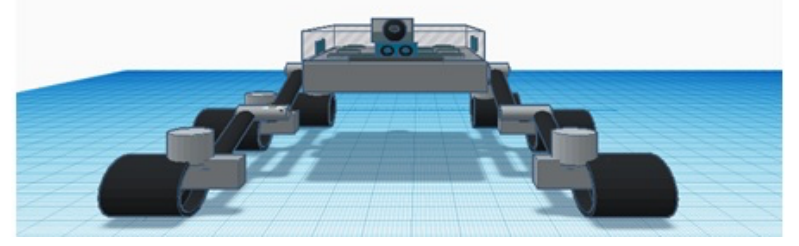

Gambar 2 Rancangan Mobile Robot Tampak Depan

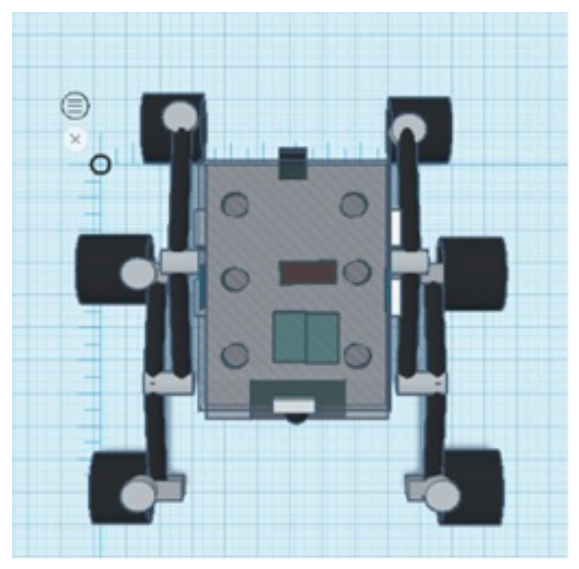

Gambar 3 Rancangan Mobile Robot Tampak Atas

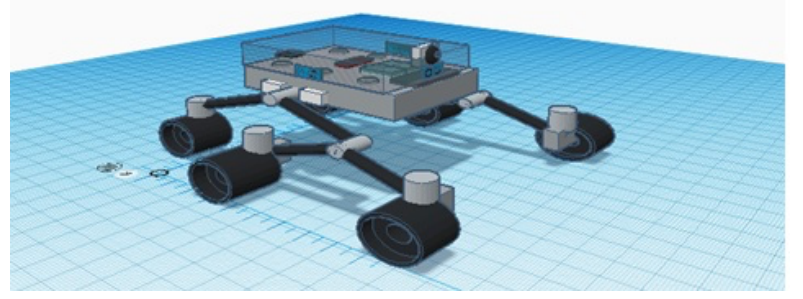

Gambar 4 Rancangan Mobile Robot Tampak Samping 
Posisi mobile robot pada Gambar 2 dan 3 dirumuskan dengan:

$$
q i=[x i, y i, \emptyset i]^{T}
$$

dimana $x i$ dan $y i$ merupakan sumbu $\mathrm{X}$ dan sumbu Y dan $\emptyset i$ adalah orientasi mobile robot terhadap sumbu $Z$. Kecepatan robot adalah:

$$
v=\left[v_{m 1}, v_{m 2}\right]
$$

dimana $v_{m 1}$ dan $v_{m 2}$ merupakan kecepatan motor kiri dan kanan.

Kontrol input yang diterapkan pada robot adalah:

$$
\mu=\frac{R}{2}\left(\dot{\theta}_{r}+\dot{\theta}_{l}\right)
$$

dimana $\theta_{r}$ dan $\theta l$ merupakan orientasi roda kanan dan kiri. $\dot{\theta}_{r}$ dan $\dot{\theta}_{l}$ adalah kecepatan sudut roda kiri dan kanan, sedangkan kecepatan sudut robot diberikan oleh:

$$
\omega=\frac{R}{2 L}\left(\dot{\theta}_{r}+\dot{\theta}_{l}\right)
$$

dimana $\dot{\theta}_{r}$ dan $\dot{\theta}_{l}$ adalah roda kanan dan kiri kecepatan sudut masing-masing. Selama pergerakan mobile robot, sensor mendeteksi rintangan dan objek yang ingin dituju agar memberikan jarak minimum yang pasti untuk mempertimbangkan input ke pengontrol untuk mendapatkan kemudi mobile robot dan berpengaruh dengan kecepatan mobile robot $\left(v_{m 1}\right.$ dan $\left.v_{m_{2}}\right)$.

Dalam penelitian ini, mobile robot diasumsikan hanya bergerak maju menghindari rintangan yang ada di depannya dan menuju target.

\subsection{Rancangan Elektrikal.}

Pada Gambar 5 menunjukkan rancangan elektrik dari mobile robot pembasmi hama. Rancangan terdiri atas Receiver stik PS2,3 buah sensor ultrasonik HC-SR04, 1 buah mikrokontroler Atmega 328, 3 buah driver motor L298 yang dipasang pararel, dan 6 buah motor DC.

Adapun fungsi dari masing-masing komponen yaitu, sensor ultrasonik sebagai pendeteksi jarak antara halangan dan objek yang akan dituju di depan mobile robot, mikrokontroler Atmega 328 sebagai otak yang memproses perintah gerak dan cara kerja robot, driver motor L298 sebagai pengatur kemudi mobile robot menentukan putaran aktuator kapan mobile robot harus berbelok, dan motor DC sebagai penggerak utama mobile robot.

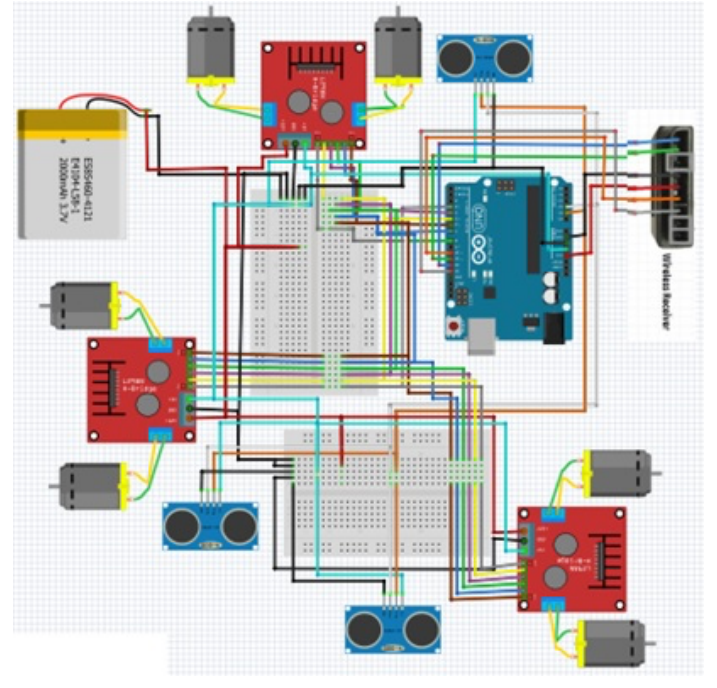

Gambar 5 Rancangan Elektrikal

\section{Hasil dan Pembahasan}

\subsection{Karakteristik Joystick Wireless PS2 Pada Robot}

Komunikasi joystick wireless PS2 memanfaatkan teknologi komunikasi wireless dengan frekuensi sinyal radio ISM $2.4 \mathrm{GHz}$ untuk menghubungkan perangkat transmitter joystick ke perangkat penerima atau receiver joystick yang relatif pendek. Komunikasi joystick wireless PS2 hanya dapat mengirim dan menerima data dengan range jarak komunikasi $2 \mathrm{~cm}$ sampai 10 meter.

Table 1 Pengujian komunikasi Transmitter dan Receiver Joystick

\begin{tabular}{|c|c|c|c|}
\hline Pengujian & $\begin{array}{c}\text { Jarak } \\
\text { (Meter) }\end{array}$ & $\begin{array}{c}\text { Dengan } \\
\text { Penghalang }\end{array}$ & $\begin{array}{c}\text { Tanpa } \\
\text { Penghalang }\end{array}$ \\
\hline 1 & 0.5 & Ya & Ya \\
\hline 2 & 1 & Ya & Ya \\
\hline 3 & 2 & Ya & Ya \\
\hline 4 & 3 & Ya & Ya \\
\hline 5 & 4 & Ya & Ya \\
\hline 6 & 5 & Ya & Ya \\
\hline 7 & 6 & Ya & Ya \\
\hline 8 & 7 & Ya & Ya \\
\hline 9 & 7.5 & Ya & Ya \\
\hline 10 & 8 & Tidak & Ya \\
\hline 11 & 8.5 & Tidak & Ya \\
\hline 12 & 9 & Tidak & Tidak \\
\hline 13 & 10 & Tidak & Tidak \\
\hline
\end{tabular}


Mayastri Devana $^{1}$, Tresna Dewi ${ }^{2}$, Nyayu Latifah Husni ${ }^{3}$, Pola Risma ${ }^{4}$, Yurni Oktarina ${ }^{5}$ Journal of Applied Smart Electrical Network and System (JASENS) Vol . 2 No. 2 (2021) 64 - 70

Table 2 Data Hasil Pengujian Navigasi Robot

\begin{tabular}{|c|c|c|c|}
\hline \multirow[t]{2}{*}{ Tombol } & \multicolumn{3}{|c|}{ Pergerakan/Perputaran Roda Robot } \\
\hline & Motor 1 & Motor 2 & Motor 3 \\
\hline \multirow[b]{2}{*}{$\leftarrow$} & $\begin{array}{l}\text { Roda Kiri : } \\
\text { mundur }\end{array}$ & $\begin{array}{l}\text { Roda Kiri : } \\
\text { mundur }\end{array}$ & $\begin{array}{l}\text { Roda Kiri : } \\
\text { mundur }\end{array}$ \\
\hline & $\begin{array}{l}\text { Roda } \\
\text { Kanan : } \\
\text { maju }\end{array}$ & $\begin{array}{l}\text { Roda } \\
\text { Kanan : } \\
\text { maju }\end{array}$ & $\begin{array}{l}\text { Roda } \\
\text { Kanan : } \\
\text { maju }\end{array}$ \\
\hline \multirow[b]{2}{*}{$\downarrow$} & $\begin{array}{l}\text { Roda Kiri : } \\
\text { mundur }\end{array}$ & $\begin{array}{l}\text { Roda Kiri : } \\
\text { mundur }\end{array}$ & $\begin{array}{l}\text { Roda Kiri : } \\
\text { mundur }\end{array}$ \\
\hline & $\begin{array}{l}\text { Roda } \\
\text { Kanan : } \\
\text { mundur }\end{array}$ & $\begin{array}{l}\text { Roda } \\
\text { Kanan : } \\
\text { mundur }\end{array}$ & $\begin{array}{l}\text { Roda } \\
\text { Kanan : } \\
\text { mundur }\end{array}$ \\
\hline \multirow[b]{2}{*}{$\rightarrow$} & $\begin{array}{l}\text { Roda Kiri : } \\
\text { maju }\end{array}$ & $\begin{array}{l}\text { Roda Kiri : } \\
\text { maju }\end{array}$ & $\begin{array}{l}\text { Roda Kiri : } \\
\text { maju }\end{array}$ \\
\hline & $\begin{array}{l}\text { Roda } \\
\text { Kanan : } \\
\text { mundur }\end{array}$ & $\begin{array}{l}\text { Roda } \\
\text { Kanan : } \\
\text { mundur }\end{array}$ & $\begin{array}{l}\text { Roda } \\
\text { Kanan : } \\
\text { mundur }\end{array}$ \\
\hline \multirow[b]{2}{*}{$\uparrow$} & $\begin{array}{l}\text { Roda Kiri : } \\
\text { maju }\end{array}$ & $\begin{array}{l}\text { Roda Kiri : } \\
\text { maju }\end{array}$ & $\begin{array}{l}\text { Roda Kiri : } \\
\text { maju }\end{array}$ \\
\hline & $\begin{array}{l}\text { Roda } \\
\text { Kanan : } \\
\text { maju }\end{array}$ & $\begin{array}{l}\text { Roda } \\
\text { Kanan : } \\
\text { maju }\end{array}$ & $\begin{array}{l}\text { Roda } \\
\text { Kanan : } \\
\text { maju }\end{array}$ \\
\hline $\mathrm{X}$ & STOP & STOP & STOP \\
\hline
\end{tabular}

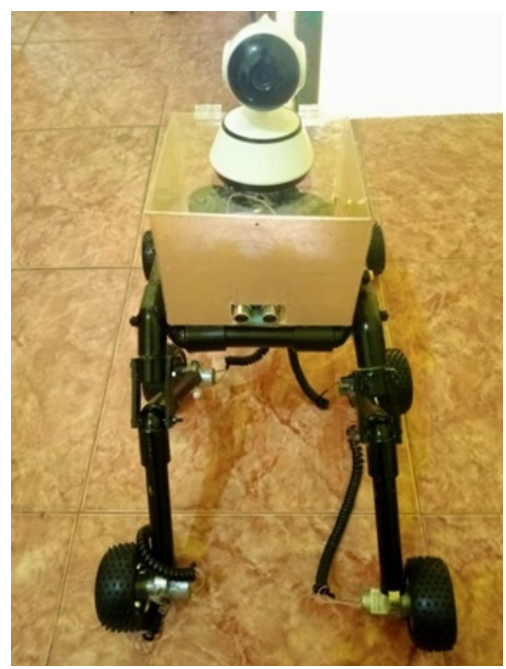

Gambar 6 Robot Pengintai Tampak Depan

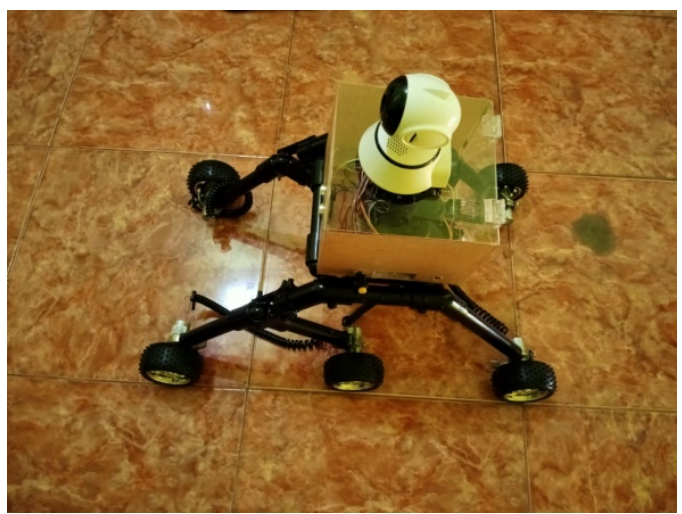

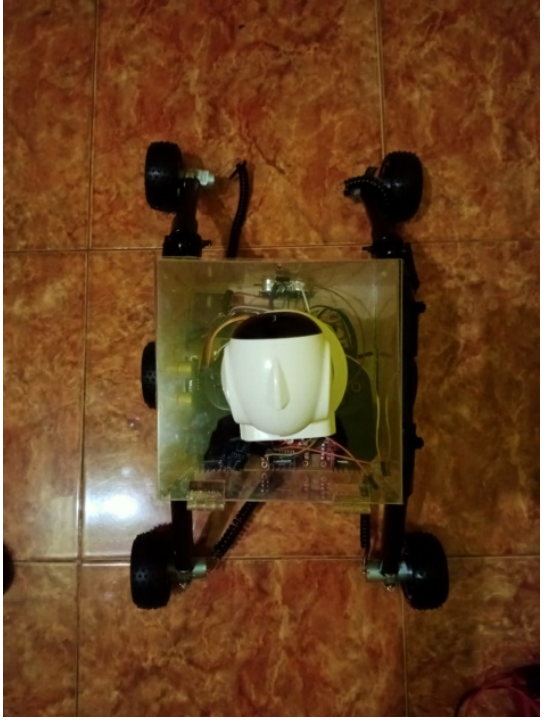

Gambar 8 Robot Pengintai Tampak Samping

3.2 Karakteristik Sensor Ultrasonic HC-SR04 Pada Robot

Sensor ultrasonik akan menembakkan gelombang ultrasonik menuju suatu area target. Setelah gelombang menyentuh permukaan target, maka target akan memantulkan kembali gelombang tersebut. Gelombang pantulan dari target akan ditangkap oleh sensor, kemudian sensor menghitung selisih antara waktu pengiriman gelombang dan waktu gelombang pantul diterima.

Table 3 Pengujian Sensor Ultrasonic

\begin{tabular}{|c|c|c|c|c|c|c|}
\hline \multirow{2}{*}{$\begin{array}{c}\text { Penguji } \\
\text { an } \\
\text { ke - }\end{array}$} & \multicolumn{2}{|c|}{$\begin{array}{c}\text { Tinggi } \\
\text { Halangan } \\
\text { dengan } \\
\text { Roda Robot }\end{array}$} & \multicolumn{3}{|c|}{$\begin{array}{c}\text { Jarak Sensor ke } \\
\text { Halangan }\end{array}$} & \multicolumn{2}{|c|}{$\begin{array}{c}\text { Pergerak } \\
\text { an Roda } \\
\text { Robot }\end{array}$} \\
\cline { 2 - 6 } & $\begin{array}{c}<\mathbf{5 c} \\
\text { m }\end{array}$ & $\begin{array}{c}>\mathbf{5 c} \\
\text { m }\end{array}$ & $\begin{array}{c}\text { Sens } \\
\text { or } \\
\text { Depa } \\
\text { n }\end{array}$ & $\begin{array}{c}\text { Sens } \\
\text { or } \\
\text { Kana } \\
\text { n }\end{array}$ & $\begin{array}{c}\text { Sens } \\
\text { or } \\
\text { Kiri }\end{array}$ & \\
\hline 1 & $\checkmark$ & & 47 & 32 & 49 & Berjalan \\
\hline 2 & & $\checkmark$ & 42 & 40 & 50 & $\begin{array}{c}\text { Berjalan } \\
\text { di tempat }\end{array}$ \\
\hline 3 & $\checkmark$ & & 39 & 33 & 25 & Stop \\
\hline 4 & $\checkmark$ & & 55 & 15 & 36 & Stop \\
\hline 5 & $\checkmark$ & & 47 & 32 & 49 & Berjalan \\
\hline 6 & & $\checkmark$ & 41 & 57 & 61 & $\begin{array}{c}\text { Berjalan } \\
\text { di tempat }\end{array}$ \\
\hline 7 & $\checkmark$ & & 38 & 46 & 12 & Stop \\
\hline 8 & $\checkmark$ & & 63 & 28 & 32 & Berjalan \\
\hline 9 & & $\checkmark$ & 50 & 78 & 60 & $\begin{array}{c}\text { Berjalan } \\
\text { di tempat }\end{array}$ \\
\hline 10 & $\checkmark$ & & 67 & 51 & 53 & Berjalan \\
\hline
\end{tabular}

Gambar 7 Robot Pengintai Tampak Samping 
Tabel 3 menunjukkan pengujian kinerja robot. Robot mampu menaiki rintangan yang kurang dari $5 \mathrm{~cm}$ dan jika rintangan lebih dari $5 \mathrm{~cm}$, maka robot akan menghindari rintangan tersebut.

Pada sensor depan robot jika membaca jarak $<40 \mathrm{~cm}$ maka robot akan di perintahkan untuk berhenti, sedangkan untuk sensor kanan dan sensor kiri pada robot jika membaca jarak $<20 \mathrm{~cm}$ maka robot akan di perintahkan untuk berhenti.

\subsection{IP Camera}

IP camera merupakan jenis kamera yang menggunakan internet protocol atau web untuk mengirimkan data gambar dan kontrol sinyal. Dalam perancangan hardware kamera digunakan sebagai penangkap gambar secara visual pada robot. Gambar yang ditangkap oleh kamera nantinya akan di proses untuk dikirim ke smartphone. IP camera dapat di gerakkan dengan smartphone dan dapat berputar 360 kekiri dan kanan, serta bergetak ke atas dan bawah $120^{\circ}$. IP camera ini juga dilengkapi dengan night vision yang akan menyala secara otomatis ketika monitoring tempat atau area yang gelap.

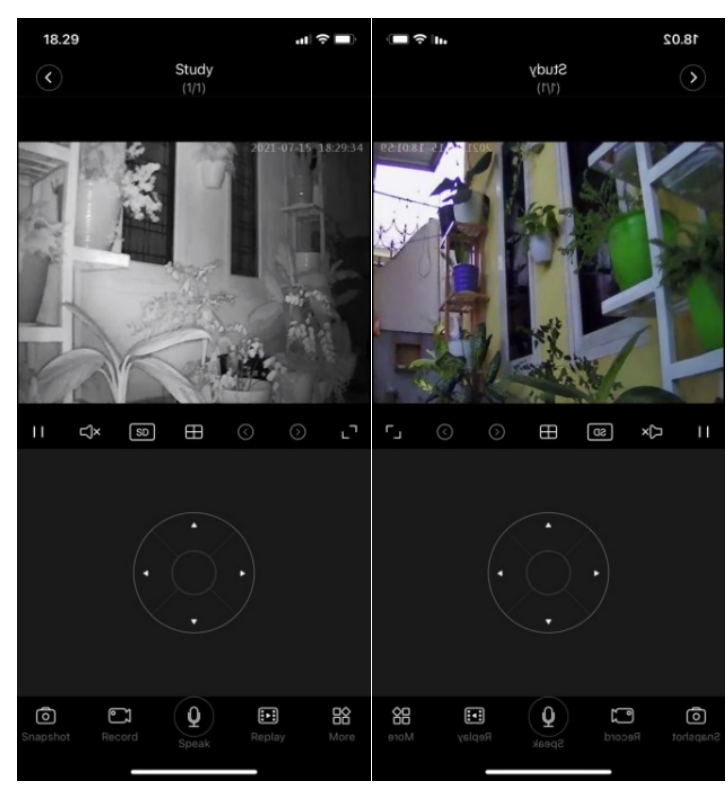

Gambar 9 Tampilan IP kamera Pada Smartphone

Gambar 9 memperlihatkan tangkapan kamera yang terpasang pada robot pada saat dioperasikan sebagai robot pengintai.

\subsection{Rancangan Simulasi Mobotsim Mobile Robot}

Pada Gambar 7 dan 8 menunjukan bahwa pada penelitian ini, pada mobile robot pengintai dengan control stick PS 2 yang diimplementasikan terbukti dengan melakukan simulasi percobaan menggunakan software mobotsim. Mobotsim merupakan software desain 2D yang dikonfigurasikan menjadi simulator mobile robot. Mobotsim ini di fungsikan untuk menunjukkan lintasan robot selama robot bergerak dari awal sampai akhir menuju target-target yang telah ditentukan [12]. Ketika proses robot bergerak menuju target, robot akan menghindari halangan yang ada disekitarnya dan akan berhenti setelah mencapai target.
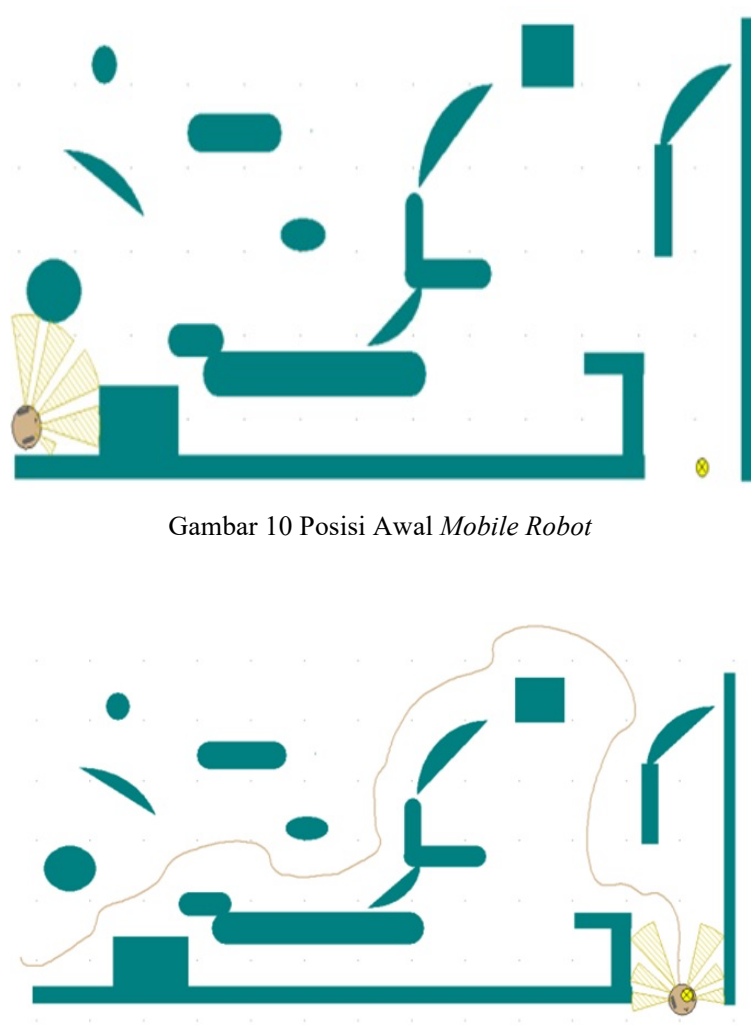

Gambar 11 Posisi Akhir Mobile Robot

\subsection{Uji Experimental Robot}

Pengujian experimental robot dilakukan untuk menguji kemampuan robot dalam bergerak pada segala bidang. Gambar 12 menunjukkan robot berjalan pada bidang tidak rata yang ditandai dengan berbagai rintangan kecil $(<5 \mathrm{~cm})$ dan rintangan besar $(>5 \mathrm{~cm})$. Seperti data yang telah ditunjukkan pada tabel 3. 

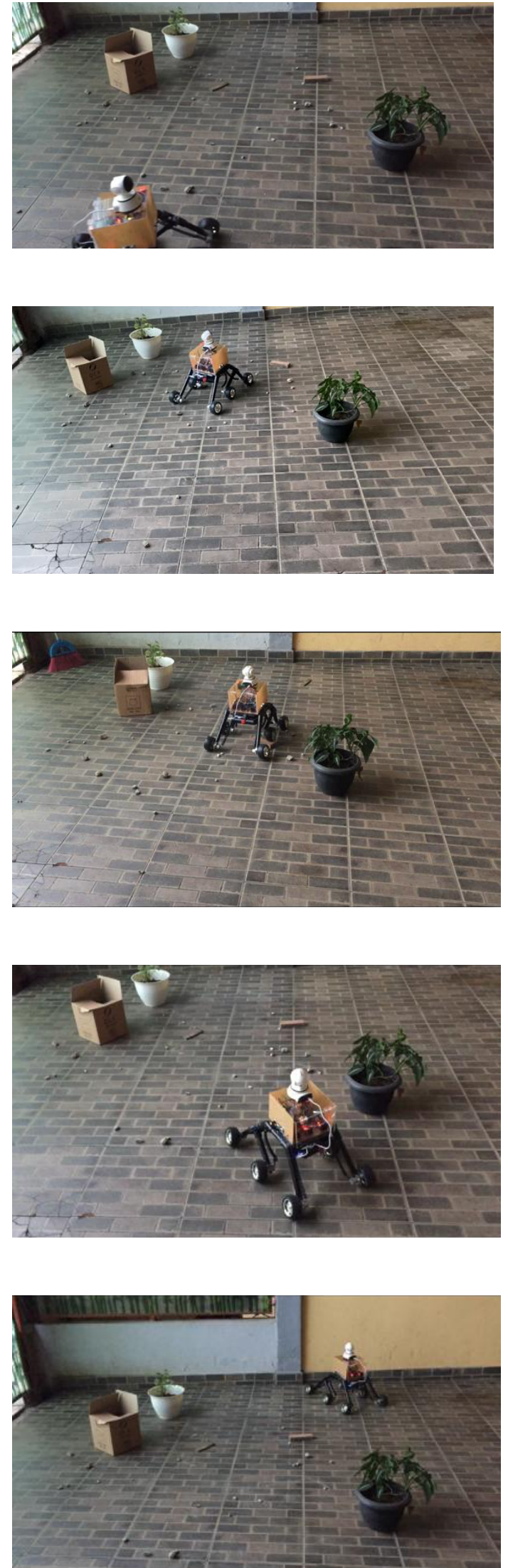

Gambar 12 Pergerakan robot pada permukan berhalang rintang

\section{Kesimpulan}

Dari penelitian yang telah dilakukan ini, mobile robot pengintai ini dibuat bertujuan untuk mengatasi kekurangan sistem kamera pengintai keamanan yang bersifat statis, yaitu rentan terdapat area titik buta pada hasil pengamatannya. Melalui penelitian ini maka dapat disimpulkan bahwa dengan bentuk robot pengintai yang menyerupai mars rover robot membuat robot ini lebih leluasa bergerak mengintai area-area dan mampu bernavigasi pada permukaan yang tidak rata. Untuk penggunaan wireless PS2 remote control memerlukan 4 pin penting yang harus berkomunikasi dengan mikrokontroler arduino yaitu pin Data, pin Command, pin Select dan pin Acknolwedge, dimana setiap merk joystick memiliki fungsi kerja yang berbeda pada pin Acknolwedge, misalnya pada joystick merk Sony pin ini harus tersambung ke Ground. Sedangkan pada joystick MTech yang dipakai pin Acknolwedge harus tersambung ke Vec 5 volt pada arduino.

Sensor ultrasonic HC-SR04 dapat berfungsi sebagai keamanan mobile robot agar tidak menabrak halangan yang ada di dekat nya dengan memasukan program robot avoider kedalam fungsi dari if dan else if pada program joystick wireless PS2 yang akan membuat robot berhenti secara otomatis ketika membaca jarak yang sudah di atur pada program.

\section{Daftar Rujukan}

[1] Dewi T., Risma P., Oktarina Y., and Muslimin S., 2018, Visual Servoing Design and Control for Agriculture Robot; a Review, pp. 57-62, Proc. 2019 ICECOS, 2-4 Oct. 2018, Pangkal Pinang: Indonesia. doi: 10.1109/ICECOS.2018.8605209.

[2] Dewi T., Risma P., and Oktarina Y., 2020, Fruit Sorting Robot based on Color and Size for an Agricultural Product Packaging System, Bulletin of Electrical Engineering, and Informatics (BEEI), 9(4), pp. 1438-1445. doi: 10.11591/eei.v9i4.2353.

[3] Dewi T., Mulya Z., Risma P., and Oktarina Y., 2021, BLOB Analysis of an Automatic Vision Guided System for a Fruit Picking and Placing Robot, International Journal of Computational Vision and Robotics, 11(3), pp. 315-326. https://doi.org/10.1504/IJCVR.2021.115161.

[4] Dewi T., Anggraini C., Risma P., Oktarina Y., and Muslikhin, 2021, Motion Control Analysis of Two Collaborative Arm Robots in Fruit Packaging System, SINERGI, 25(2), pp. 217-226. http://doi.org/10.22441/sinergi.2021.2.013

[5] Oktarina Y., Dewi T., Risma P., and Nawawi M., 2020, Tomato Harvesting Arm Robot Manipulator; a Pilot Project, Journal of Physics: Conference Series, 1500, p 012003, Proc. $3^{\text {rd }}$ FIRST, Palembang: Indonesia.

[6] Al Yahmedi A.S., and Fatmi M.A., 2016. Fuzzy Logic Based Navigation of Mobile Robots," Intech, 6, pp. 111133.

[7] Oktarina Y., Septiarini F., Dewi T., Risma P., and Nawawi M., 2019, Fuzzy-PID Controller Design of 4 DOF Industrial Arm Robot Manipulator, Computer Engineering and Application Journal, 8(2), pp. 123-136. doi: 10.18495/COMENGAPP.V8I2.300.

[8] Uchiyama N., Dewi T., Sano S., and Takahashi H., 2014, Swarm Robot Control for Human Services and Moving Rehabilitation by Sensor Fusion, Journal of Robotics,

Journal of Applied Smart Electrical Network and Systems (JASENS) 
2014(278659),

11

https://doi.org/10.1155/2014/278659.

pages.

[9] Dewi T., Uchiyama N., Sano S., and Takahashi H., 2014, Swarm Robot Control for Human Services and Moving Rehabilitation by Sensor Fusion, Journal of Robotics, 2014, 278659(11). DOI: 10.1155/ 2014/278659

[10] Dewi T., Risma P., Oktarina Y., and Kusumanto RD., 2019, Motion Control Analysis of a Spherical Robot as a Surveillance Robot, Journal of Physics: Conference Series, 1167(1), 012004

[11] Oktarina Y., Dewi T., and Risma T., 2020, The Concept of Automatic Transport System Utilizing Weight Sensor, Computer Engineering and Application Journal, 9(2), pp. 155-163. doi:10.18495/COMENGAPP.V0I0.339

[12] Dewi T., Risma P., Taqwa A., Rusdianasari, and Renaldi H., 2020, Experimental analysis on solar powered mobile robot as the prototype for environmentally friendly automated transportation, Proc. iCAST on Engineering Science, 24-25 Oct 2019, Bali: Indonesia, doi:10.1088/1742-6596/1450/1/012034.

[13] Dewi T., Amperawan, Risma P., Oktarina Y., and Yudha D. A., 2020, Finger Cue for Mobile Robot Motion Control, Computer Engineering and Application Journal, 9(1), pp. 39-48. doi: 10.18495/COMENGAPP.V9I1.319.

[14] Dewi T., Oktarina Y., Risma P., and Kartini S., 2019 Desain Robot Pengikut Manusia Sederhana dengan Fuzzy Logic Controller, Proc. Annual Research Seminar (ARS), 5(1), pp. 12-16, 16 Nov 2019, Palembang: Indonesia.

[15] Hendrix R., Owan P., Garbini J., and Devasia S., 2019. Context-Specific Separable Gesture Selection for Control of a Robotic Manufacturing Assistant. IFAC PapersOnline, 51(34), pp. 89-96.

[16] Syahrian N. M., Risma P., and Dewi T., 2017, VisionBased Pipe Monitoring Robot for Crack Detection using Canny Edge Detection Method as an Image Processing Technique, Kinetik: Game Technology, Information System, Computer Network, Computing Electronics, and Control, 2(4), pp. 243-250.

[17] Uchiyama N., Dewi T., and Sano S., 2014, Collision Avoidance Control for a Human-Operated Four Wheeled Mobile Robot, Proceedings of the Institution of Mechanical Engineers, Part C: Journal of Mechanical Engineering Science, 228(13), pp. 2278-2284. https://doi.org/10.1177/0954406213518523.

[18] Nurmaini S., Tutuko B., Dewi K., Yuliza V., and Dewi T., 2017, Improving Posture Accuracy of Non-holonomic Mobile Robot system with Variable Universe of Discourse, TELKOMNIKA， 15(3). Pp. 1265-1279. doi: 10.12928/TELKOMNIKA.v15i3.6078.

[19] Dewi T., Wijanarko Y., Risma P., and Oktarina Y., 2018, Fuzzy Logic Controller Design for Leader-Follower Robot Navigation, $5^{\text {th }}$ Proc. EECSI, 5(1), pp. 298-303. 16-18 Oct 2018, Malang : Indonesia. doi:10.1109/EECSI.2018.8752696.
[20] Dewi T., Risma P., and Oktarina Y., 2018, Fuzzy Logic Simulation as a Teaching-learning Media for Artificial Intelligence Class, Journal of Automation Mobile Robotics and Intelligent Systems, 12(3), pp. 3-9, 2018, DOI: 10.14313/JAMRIS $\backslash 3-2018 / 13$

[21] Dewi T., Sitompul C., Risma P., Oktarina Y., Jelista R., Mulyati M., 2019, Simulation Analysis of Formation Control Design of Leader-Follower Robot Using Fuzzy Logic Controller, Proc 2019 ICECOS, 2-3 Oct. 2019, Batam Island: Indonesia. doi:10.1109/ICECOS47637.2019.8984433.

[22] Farooq U., Amar M., Asad M.U., Hanif A., and Saleh S.O., 2014. Design and Implementation of Neural Network of Based Controller for Mobile Robot Navigation in Unknown Environment. International Journal of Computer and Electrical Engineering, 6(2), pp. 83-89. doi:10.7763/IJCEE.2014.V6.799

[23] Yudha H. M., Dewi T., Hasana N., Risma P., Oktarina, Y. Kartini S., 2019, Performance Comparison of Fuzzy Logic and Neural Network Design for Mobile Robot Navigation, Proc. 2019 ICECOS, 2-3 Oct. 2019, Batam Island: Indonesia. doi:10.1109/ICECOS47637.2019.8984577

[24] Larasati N., Dewi T., and Oktarina Y., 2017. Object Following Design for a Mobile Robot using Neural Network. Computer Engineering and Application Journal, 6(1), pp. 5-14. doi:10.18495/COMENGAPP.V6I1.189.

[25] Dewi T., Risma P., Oktarina Y., and Roseno M.T., 2017. Neural Network Design for a Mobile Robot Navigation a Case Study. 4th Proc. EECSI. 23-24 Sep. 2017. Yogyakarta: Indonesia. doi:10.1109/EECSI.2017.8239168.

[26] Dewi T., Risma P., Oktarina Y., and Nawawi M., 2017. Neural Network Simulation for Obstacle Avoidance and Wall Follower Robot as a Helping Tool for TeachingLearning Process in Classroom. 1st Proc. ICEAT, 29-30 November 2017, Mataram: Indonesia. doi:10.1088/1757899X/403/1/012043

[27] Risma P., Dewi T., Oktarina Y., and Wijanarko Y., 2019. Neural Network Controller Application on a Visual based Object Tracking and Following Robot. Computer Engineering and Application Journal, 8(1). doi: 10.18495/COMENGAPP.V8I1.280.

[28] Kuswad S., Natasya A., Tamara M.N., and Adji I., 2018. Optimasi Sistem Navigasi Robot Bencana Dengan Algoritma Bug Dan Jaringan Syaraf Tiruan. JTIIK, . 5(5), pp. 635-642.

[29] Savage J., Muoz S., Matamoros M., and Osorio R., 2013 Obstacle Avoidance Behaviors for Mobile Robots Using Genetic Algorithms and Recurrent Neural Networks. IFAC, 46(24), pp. 141-146.

[30] A. Hariyadi, Y. Ratnawati, and R. H. Y. Perdana, "Jurnal iptek," J. IPTEK, vol. 24, no. 1, pp. 11-18, 2018, doi: 10.31284/j.iptek.2020.v24i1. 